\title{
Therapeutic management of anemia due to trypanosomosis in dogs
}

\begin{abstract}
Trypanosomosis is one of the fatal diseases in canines. Inappropriate usage of the trypanosomacidal drugs leads to development of the resistance organisms. Present communication report the successful treatment of the clinical trypanosomosis with two doses of injection diminazene aceturate at the rate of $3.5 \mathrm{mg} / \mathrm{kg}$ body weight intramuscularly. Two dogs with clinical trypanosomosis were noticed with the signs of fever; tachycardia and tachypnea congested mucus membranes, corneal opacity and enlarged lymph nodes. Dogs revealed lowered the red blood cell count, hemoglobin, packed cell volume, serum total protein; albumin and glucose levels. Trypanosoma evansi organisms were noticed in the blood smears. The clinical and biochemical improvement was recorded in both the dogs and dogs were free from anemia after one month of therapy.
\end{abstract}

Keywords: anaemia, trypanosoma evansi, dog, diminazene aceturate
Volume 5 Issue 3 - 2017

\section{Sivajothi S,' Sudhakara Reddy B²}

'Department of Veterinary Parasitology, Sri Venkateswara Veterinary University, India

2Department of Veterinary Clinical Complex, Sri Venkateswara Veterinary University, India

Correspondence: Sirigireddy Sivajothi, Assistant Professor, Department of Veterinary Parasitology, College of Veterinary Science, Proddatur-516360, Sri Venkateswara Veterinary University, Andhra Pradesh, India, Email sivajothi579@gmail.com

\section{Introduction}

Trypanosomosis is a haemoprotozoan disease of domestic and wild animals, spread by tabanid flies bites. The disease generally causes fever, anemia, myocarditis, corneal opacity and it is a fatal disease in canines. ${ }^{1}$ Now a day's many numbers of trypanosomacidal drugs are available including suramin, quinapyramine and diminazene. But, a single dose of the drug is not effective for horses, mules and dogs since diminazene aceturate neither crosses the blood-brain barrier nor insufficient doses were unable to control the T. evansi infection. ${ }^{2,3}$ Present communication; put a record on the therapeutic efficacy of two doses of diminazene aceturate injections to treat dogs with $T$. evansi infection.

\section{Materials and methods}

Two adult dogs were presented to the Hospital with a history of inappetence, dullness, progressive emaciation, corneal opacity, congested mucus membranes, and persistent fever. Both the dogs were treated with antibiotics and antipyretics at local hospitals with partial relief of symptoms. Clinical examination of the dogs revealed elevated rectal temperature, pulse rate, respiratory rate; pale and congested mucous membranes, corneal opacity, bilateral lacrimation and generalized debility (Figures $1 \&$ Figure 2). Peripheral blood was collected and examined under light microscopy for haemoprotozonas which revealed the presence of motile trypanosomes. Microscopic examination of Giemsa stained blood smear revealed the presence of Trypanosoma evansi organisms in between the red blood cells (Figure 3). Further blood was collected for haematological and biochemical analysis. ${ }^{4}$ Dogs were treated with two doses of injection diminazene aceturate@3.5mg/kg body weight intra muscularly at 96hours interval, inj. meloxicam @ $0.3 \mathrm{mg} / \mathrm{kg}$ body weight subcutaneous for first three days, five doses of inj. iron dextran (imferon) $10 \mathrm{mg} / \mathrm{kg}$ body weight intramuscularly at 48 hours interval and oral supplementation of iron containing syrup (Dexorange) @10gram per day daily. Posttreatment, the parasitemia was estimated by direct microscopic examination of blood and stained smears.

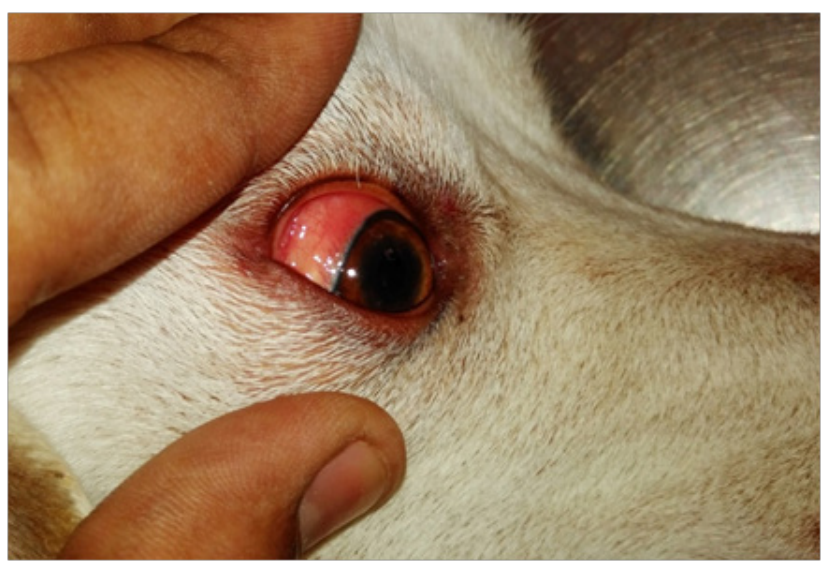

Figure I Dog suffering with trypanosomosis-congested bulbar conjunctiva

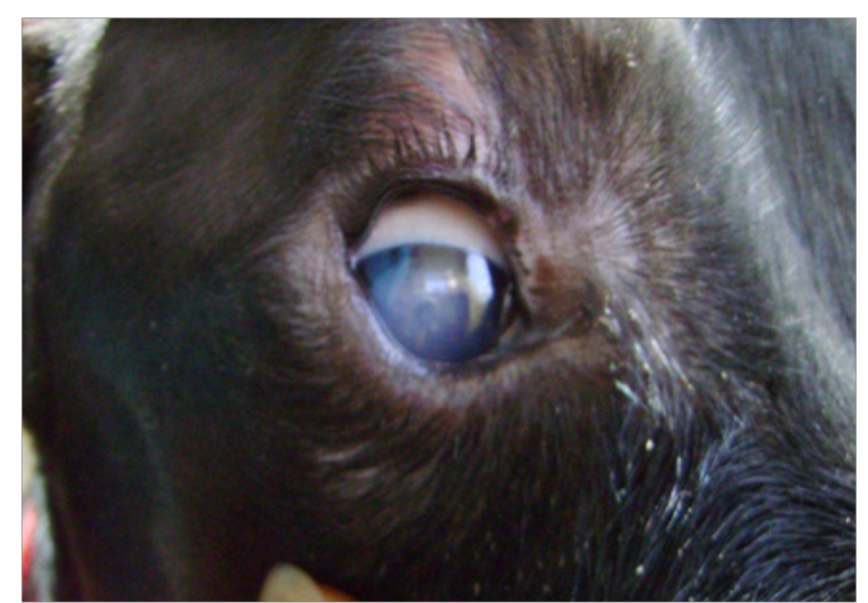

Figure 2 Dog suffering with trypanosomosis-corneal opacity. 


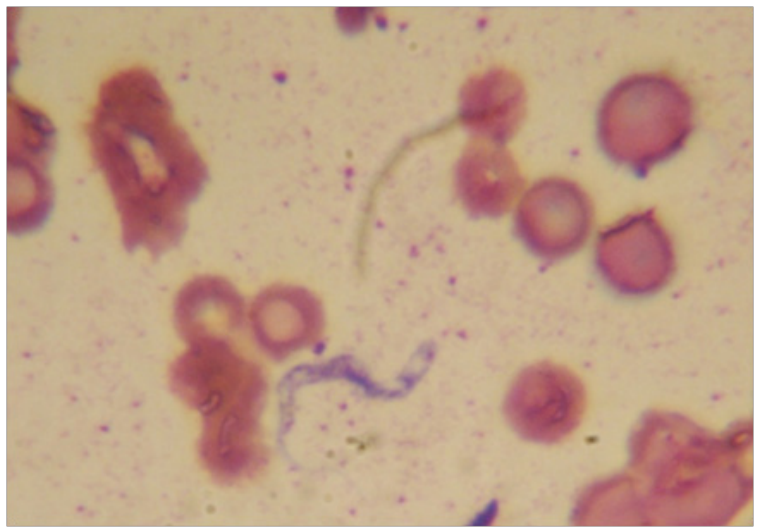

Figure 3 Microscopic examination of stained blood smears.

\section{Results and discussion}

Microscopic examination of blood smears revealed $24.3 \pm 2.62$ microns length trypanosome with sub-terminal kinatoplast with undulating membrane. The kinatoplast of the parasites were sub-terminal, the undulating membranes were well developed and there was a substantial free flagellum. Based on the morphology and micrometry it was confirmed as Trypanosoma evansi. ${ }^{5}$ Haematological finding were in two dogs were as haemoglobin $(6.6,5.4 \mathrm{~g} / \mathrm{dL})$, total erythrocyte count $\left(3.4 \mathrm{X} 10^{6}, 3.1 \mathrm{X} 10^{6} \mu \mathrm{L}\right)$, packed cell volume $(18 \%, 17.4 \%)$ and higher total leucocyte count $(9800,11200 / \mu \mathrm{L})$, neutrophils (42-38\%), eosinophils (6-4\%), lymphocytes $(51,57 \%)$ and monocytes $(1,1 \%)$. Biochemical findings were glucose $(53,68 \mathrm{mg}$ / $\mathrm{dL})$, total protein $(5.43,5.66 \mathrm{mg} / \mathrm{dL})$, albumin $(1.79,1.62 \mathrm{mg} / \mathrm{dL})$, blood urea nitrogen $(48.12,56.60 \mathrm{mg} / \mathrm{dL})$ and creatinine $(2.20,2.86 \mathrm{mg} / \mathrm{dL})$.
Recorded haemato-biochemical findings before and after therapy were presented in the Table 1. By the seventh day of treatment, clinical signs were disappeared and the parasites were not found in blood smears.

The severity of canine trypanosomosis ranges from acute, subacute to chronic forms. In dogs an acute and fatal type is commonly seen and death possibly occurs in 2-4weeks after infection. During the course of pathogenesis, organisms enter host cells after infection, multiplies sub-clinically, escapes the immune system and parasitemia develops within a few days and peaks 2 to 3 weeks post-infection. ${ }^{6}$ During the chronic infection, progressive weakness, anorexia, anaemia, intermittent fever, conjunctivitis, swelling of limbs, enlarged superficial lymph nodes and bilateral corneal opacity are noticed. ${ }^{7}$ Haemato-biochemical findings observed in the present study were in according with the previous studies and the anaemic changes are attributable to extra vascular destruction of red blood cell which may be through the process of erythrophagocytosis or metabolic product and toxins liberated from the parasites. Hypoglycaemia was noticed in these dogs and it is due to utilization of blood glucose by parasites in circulation. Observed reduced serum albumin levels were may be due to decreased liver biosynthesis and progressive loss of albumin in urine. ${ }^{4}$ Due to tissue damage and kidney dysfunction, uremia and elevated creatinine levels were noticed in the present study. ${ }^{8}$ Diminazene aceturate is the commonly used drug to control trypanosomosis in animals in Africa which have been in use for over 40years. ${ }^{9}$ Mechanism of action of this drug involved the disruption of DNA synthesis, inhibition of adenosylmethionine decarboxylase or related processes. ${ }^{10}$ Recently, diminazene aceturate resistant Trypanosoma evansi organisms isolated from a buffalo. ${ }^{11}$ Two doses of diminazene aceturate were given intra muscularly at a dosage of $3.5 \mathrm{mg} / \mathrm{kg}$ body weight were effective for $T$. evansi infections in dogs.

Table I Haematological and biochemical assessment during the treatment

\begin{tabular}{|c|c|c|c|c|c|c|c|c|c|c|}
\hline \multirow[t]{2}{*}{ Parameters } & \multicolumn{2}{|c|}{$0^{\text {th }}$ Day } & \multicolumn{2}{|c|}{$7^{\text {th }} 9^{\text {th }}$ Day } & \multicolumn{2}{|c|}{$14^{\text {th }}-17^{\text {th }}$ Day } & \multicolumn{2}{|c|}{$21^{\text {st }}$ Day-22 ${ }^{\text {nd }}$ Day } & \multicolumn{2}{|c|}{$28^{\text {th }}$ Day-33 ${ }^{\text {rd }}$ Day } \\
\hline & Dog-1 & Dog-2 & Dog-1 & Dog-2 & Dog-1 & Dog-2 & Dog-1 & Dog-2 & Dog-1 & Dog-2 \\
\hline $\mathrm{Hb}(\mathrm{gm} \%)$ & 6 & 5.4 & 7.1 & 6.6 & 8.4 & 7.8 & 9.2 & 8.2 & 11 & 10.4 \\
\hline $\operatorname{PCV}(\%)$ & 18 & 17.4 & 23 & 19 & 26 & 26 & 28 & 28 & 34 & 36 \\
\hline Albumin(g/dL) & 1.79 & 1.62 & 2.1 & 1.68 & 2.7 & 1.98 & 2.8 & 2.4 & 3.2 & 2.9 \\
\hline Total protein(g/dL) & 5.43 & 5.66 & 7.21 & 7.22 & 7.8 & 7.67 & 8.2 & 8.4 & 8.3 & 8.4 \\
\hline Glucose(mg/dL) & 53 & 68 & 70 & 54 & 110 & 96 & 142 & 92 & 138 & 112 \\
\hline
\end{tabular}

\section{Conclusion}

Uneventful recovery was noticed in dogs suffering from anemia caused by trypanosomosis by using two doses of diminazene aceturate along with the iron supplements.

\section{Acknowledgements}

The authors are thankful to the authorities of Sri Venkateswara Veterinary University for providing the facilities to carry out the work.

\section{Conflicts of interest}

The author declares there are no conflicts of interest.

\section{References}

1. Reddy BS, Kumari KN, Sivajothi S, et al. Haemato-biochemical and thyroxin status in Trypanosoma evansi infected dogs. J Parasit Dis. 2016;40:491-495.

2. Tuntasuvan D, Jarabrum W, Viseshakul N, et al. Chemotherapy of surra in horses and mules with diminazene aceturate. Vet Parasitol. $2003 ; 110(3): 222-233$.

3. Herrera HM, Davila AM, Norek A, et al. Enzootiology of Trypanosoma evansi in pantanal, Brazil. Vet Parasitol. 2004;125(3-4):263-275.

4. Sivajothi S, Rayulu VC, Reddy BS. Haematological and biochemical changes in experimental Trypanosoma evansi infection in rabbits. $J$ Parasit Dis. 2015;39:216-220. 
5. Sivajothi S, Rayulu VC, Reddy BS. Rapid serodiagnosis of Trypanosoma evansi in dogs by colloidal dye immunobinding assay. Comp Clin Pathol. 2015;24(6):1497-1500.

6. Sivajothi S, Reddy BS. Trypanosoma evansi infection in a cat-a rare case. Comp Clin Pathol. 2007.

7. Soulsby EJL. Helminths, Arthropods and protozoa of domesticated animals. 7th ed. London: Bailliere Tindal; 1982. 533 p.

8. Aquino LPCT, Machado RZ, Alessi AC, et al. Hematological, biochemical and anatomopathological aspects of the experimental infection with Trypanosoma evansi in dogs. Arq Bras Med Vet Zootec. 2002;54(1).
9. Geerts S, Holmes PH, Eisler MC, et al. African bovine trypanosomiasis: the problem of drug resistance. Trends Parasitol. 2001;17:25-28.

10. Balana Fouce R, Garzon PT, Ordonez Esoudero D, et al. Inhibition of diamine oxidase and S-adenosylmethionine decarboxylase by diminazene aceturate (berenil). Biochem Pharmacol. 1986;35(9):1597-1600.

11. Sivajothi S, Reddy BS. Polypeptide profiles of diminazene aceturate resistant Trypanosoma evansi organisms isolated from a buffalo. $J$ Veter Sci Med. 2016;4(1):1-4. 